Review Article

\title{
Overview of health risk communication strategies in the context of COVID-19 vaccination in India
}

\author{
Anuradha Kunal Shah, Swarnika Pal*
}

Department of Community Medicine, Seth GS Medical College and KEM Hospital, Mumbai, Maharashtra, India

Received: 22 November 2021

Accepted: 12 January 2022

\author{
*Correspondence: \\ Dr. Swarnika Pal, \\ E-mail: swarnikapal19@gmail.com
}

Copyright: (c) the author(s), publisher and licensee Medip Academy. This is an open-access article distributed under the terms of the Creative Commons Attribution Non-Commercial License, which permits unrestricted non-commercial use, distribution, and reproduction in any medium, provided the original work is properly cited.

\begin{abstract}
Vaccines are being considered as the most promising approach to curb the COVID-19 pandemic. Drug Controller General of India (DCGI) authorized restricted emergency use of two vaccines, Covishield and Covaxin on $3^{\text {rd }}$ January 2021. The vaccination drive in India was launched on 16th January 2021. Conducting vaccination at this scale in a country like India is a daunting task because of inherent demographical challenges comprising different ages, incomes, and linguistic profiles of people. An effective health risk communication (HRC) strategy is highly important to reach out to the masses and make them realize the importance of vaccination. It is a crucial pillar for developing national core capacity during emerging infectious diseases. Studying the five months post vaccine rollout in India and assessing the communication strategies based on the principles of HRC is going to provide us good insights into how India has fared in this context. Efforts for COVID-19 vaccination have reached a crucial juncture with the roll-out of vaccination for the largest age group of 18-44 years since $1^{\text {st }}$ May 2021. Transparent, clean and precise answers about facts are either known or unknown, need to be maintained. Vaccine-related myths and higher reporting of deaths due to unknown causes must be stopped. The media must proof check all vaccine-related news with relevant and confirmed scientific materials only and present it with the necessary disclosures. This review focussed on an overview of health risk communication strategies in the context of COVID-19 vaccination in India.
\end{abstract}

Keywords: Communication strategies, COVID-19 vaccination, Health risk

\section{INTRODUCTION}

Coronavirus disease 2019 (COVID-19) was declared a global health emergency by World Health Organization (WHO) on $30^{\text {th }}$ January 2020 and since then the world has just seen the worst, with intermittent waves shaking the health structure. Amidst, this pandemic, vaccination is an important intervention for reducing mortality and morbidity. It is also the solution for the financial crisis countries are going through. ${ }^{1}$ To have the best effect, vaccines need to be offered quickly and in large quantities. COVID-19 vaccines have been fast-tracked by regulatory authorities. ${ }^{2}$

Health risk communication (HRC) is a critical pillar for developing national core capacity during emerging infectious diseases as per the International Health
Regulation (IHR), 2005. The right information delivered the right way at right time is essential during an emergency so that people can make an informed choice to protect themselves. ${ }^{3}$ The aim of HRC strategy for vaccination is to generate awareness, trust and to invalidate any rumours/misconceptions/misbeliefs amongst the public. ${ }^{4}$ In a country like India, reaching out to the masses is extremely difficult as different communities have different communication needs. Communication is a good tool, however, if it is not controlled and any source which misinforms the public, may result in outrage and distrust against the system.

\section{RISK PERCEPTION AND TACKLING}

The goal of HRC is to manage public reaction and prepare them for appropriate actions to reduce the risk. 
COVID-19 vaccines are being helmed as the key to controlling the pandemic. However, vaccine hesitancy could become a major threat to its rollout. A key determinant in decision regarding vaccine is the risk people associate with the disease the vaccine protects against. Another equally important factor is the perceived safety of the vaccine. Effective risk communication addresses these aspects. ${ }^{5}$

Past experiences with vaccination drive in India have met with its share of trust as well as hesitancy. However, the human papillomavirus vaccine trials lacked transparency and due to poor communication, awareness was low among the beneficiary group too. ${ }^{6}$ Similarly, misinformation about the polio vaccine may have caused roadblocks that have been met effectively with better and consistent communication. The universal immunization program (UIP) which is the largest mass vaccination campaign for under-five children has successfully garnered trust by effective use of mass communication and social media. ${ }^{7}$ Valuable lessons from these experiences show the importance of HRC in COVID-19 vaccination too.

The target population for COVID-19 vaccination is the whole population above the age of 18 years hence; they become the target audience for HRC. This includes the healthcare workers (HCWs) and other hospital staff too who are the most vulnerable and first point of contact for vaccination. Special groups including migrant population, poor socio-economic strata, religious minorities, sexual minorities are also part of it. Tailor-made HRC strategies based on the audience's intellect, beliefs, reservations, and considering the socio-economic-cultural-linguistic barriers are needed. All stakeholders should be sensitized and play their respective part in HRC.

\section{RISK COMMUNICATION IN THE CONTEXT OF COVID-19 VACCINATION}

The ministry of health and family welfare (MoHFW) published the 'COVID-19 vaccine communication strategy' to guide the stakeholders, program managers in planning effective HRC strategies on January $1^{\text {st, }} 2021 .^{4,8}$ It is about eight months since the vaccine rollout, and assessing the communication strategies based on the principles of HRC will give a good insight into how India has fared in this context.

\section{TIMING}

In a high-level meeting chaired by the honourable Prime Minister, attended by Cabinet Secretary, Principal Secretary to Prime Minister, Health Secretary, and other senior officials concerned on $9^{\text {th }}$ January 2021, announcement of vaccination rollout in the entire country on $16^{\text {th }}$ January 2021 was made. ${ }^{9}$ The vaccination drive was planned in a phased manner. Priority was given to the healthcare workers and frontline workers (FLWs). The timeline of the entire process is given in Figure 1. The mode of communication used was traditional as well as digital platforms and public feedback was collected through remote means like SMS, GOI Chatbox, and Twitter handle of Ministry of information and broadcasting and Health Minister were used for communication. $^{10-12}$ COVID-19 National and State Helpline Call Centres (1075 and 104) were also used. ${ }^{4}$ While this was happening the government had become somewhat complacent at the end of the first wave, and vaccine procurement plans were delayed. Needed investment and push was not given to vaccine manufacturers in time like it was in the case of western countries. Also, emergency base approval for all the vaccines could have been given earlier as done in other countries.

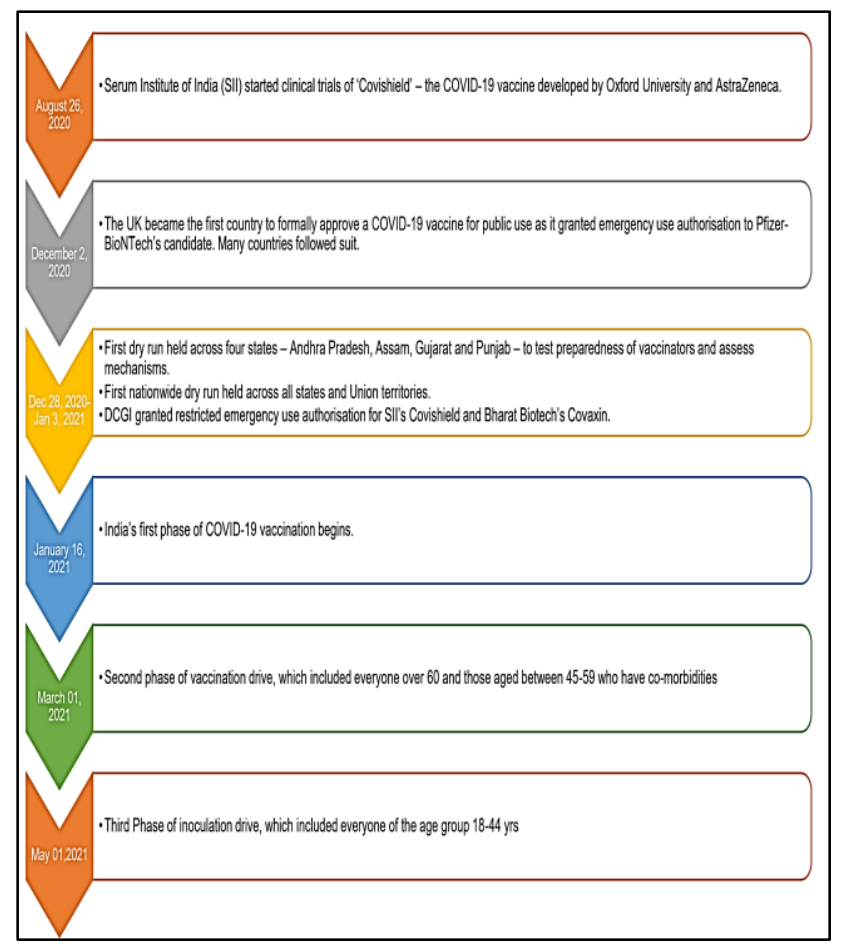

Figure 1: Timeline of vaccine.

\section{TRUST}

A survey conducted just a few months before the vaccine rollout shows that $87 \%$ of Indians wanted to receive the vaccine when available. ${ }^{13}$ This shows the trust in vaccines. However, it cannot be taken for granted. Factors that played a role in shaping the trust are the speed at which candidate vaccines received approval and their safety, the unscientific claims following approval, and the duration of the immune response following vaccination. ${ }^{14}$ Effective HRC by a trusted source targeting these factors should be done. People put their trust in the leader of the state or country. Media and community leaders also are looked upon by the people for guidance. They can be key to galvanizing public opinion about obeying rules and regulations to control the pandemic. Sadly, both political leaders and religious leaders in India have neglected to gather support for Covid appropriate behaviour (CAB) as 
well as reducing hesitancy for vaccination. At this point in time, HCWs are instinctive choices to fill this leadership vacuum. ${ }^{15}$ During the first phase of vaccine roll-out, healthcare workers which included doctors and nursing staff became the priority group. The turnout was low during the initial phase which has may have impacted the public's decision regarding vaccination. ${ }^{16,17}$ However, the latest scientific reports have shown good acceptance. ${ }^{18,19}$ These findings need to be highlighted so that trust is built among other eligible groups. Targeted interventions roping in community leaders of religious and sexual minority groups to build on trust in their respective communities are required.

\section{TRANSPARENT}

Transparency in the form of easy visibility and accessibility of information regarding the development, procurement, and distribution of COVID-19 vaccines will contribute towards building trust. On $3^{\text {rd }}$ January 2021, Covishield, a vaccine developed by Serum Institute of India (SII) using the technology transfer from AstraZeneca/Oxford university was approved for restricted use in emergencies based on immunogenicity, safety, and efficacy data generated from overseas clinical studies and from an interim study, conducted by the SII, on 1600 participants, which were found comparable. The overall vaccine efficacy turned out to be $70.42 \%$. Although, the interim study data is still not available on the public platform. Covaxin, developed by Bharat Biotech in collaboration with the Indian Council of Medical Research (ICMR) and National Institute of Virology (NIV) was approved based on phase 1 and 2 clinical trials, but no efficacy data was shared. ${ }^{20}$ The preprint of the interim phase 3 result was released in July $2021 .^{21}$ In addition to these two, Sputnik-V vaccine, developed by $\mathrm{M} / \mathrm{s}$ Gamaleya Institute, Russia, with an efficacy of $91.6 \%$ as per the interim study, was granted permission for restricted use in an emergency by the drug regulators on $13^{\text {th }}$ April 2021.22

Transparency should also be maintained in the pricing of vaccines if public money has been used in their development. On $1^{\text {st }}$ May 2021, "Liberalised Pricing and Accelerated National COVID-19 Vaccination Strategy" for phase 3 was adopted. This strategy aimed to incentivize the vaccine manufacturers to increase their production, resulting in flexibility in pricing, procurement, and improved coverage. Earlier, the central government procured the vaccine and distributed it to the states. Now, as per the phase 3 strategy, $50 \%$ of the vaccine doses would mandatorily go to the centre and the rest will be divided between states and private healthcare providers. The manufacturers were given the freedom to raise the prices for state governments and private healthcare providers but for the centre, the price was kept the same (Rs.150/- per dose). This step placed the state governments at a disadvantage while negotiating with the manufactures. Besides, there is an inherent issue of equivalence associated with the same vaccine being supplied at two different prices to two public procurement agencies, which will be serving the same beneficiaries. High prices of vaccines, fixed by manufacturers set a bad example for ensuring transparency in pharmaceutical pricing, that too during vital public health situations. However, the vaccines are provided free of cost to the beneficiaries at Government vaccination centres. On $7^{\text {th }}$ June 2021, the Prime Minister announced free vaccines to all citizens above the age of 18 years, and that the central government will be procuring $25 \%$ of vaccines that were with the states. With this Govt. of India (GOI) would end up procuring $75 \%$ of total vaccine production and provide it to the states free of cost. ${ }^{23}$

All Covid vaccination (public or private) are part of the National vaccination programme and are directed to follow all protocols and other prescribed norms set by GOI. The MoHFW launched the CoWin portal for realtime IT-based tracking of vaccine logistics. ${ }^{24}$ The MoHFW website, Press Information Bureau (PIB) reports, India vaccine tracker site act as a medium to publicize all the relevant information related to vaccination. It addresses frequently asked questions, key modifications in vaccination policy, total number vaccinated, side-effects, myths, vaccine stocks, and adverse events following immunization (AEFI). However, information about the number and severity of breakthrough infections has not been shared publicly via a trusted source that the media has been reporting. If the correct information is shared it would build trust in rural India who fears that due to vaccination people are developing the COVID-19 disease. "The CoWIN app could have been designed to track the relationship between vaccination," as suggested by one of the members of the COVID working group, but this wasn't paid heed to. ${ }^{25}$

Data against the efficacy of the vaccine against mutant strains are not available but speculations regarding this are many. India follows a dynamic mapping model based on the availability of vaccines and coverage of vulnerable priority groups to decide when to open vaccinations to different age groups. As the priority groups were set, message was conveyed with reasons. It was accepted without any conflict by the whole population and there was no further media debate. Yet, there were instances of power abuse, that few public figures have got the vaccine when they were not in that priority group. ${ }^{26}$ There have also been frequent changes in the interval between two doses of Covishield. The time gap for the general public is $12-16$ weeks but for people travelling abroad for study and employment purpose was made after 4 weeks. This has led to people wondering if policies are being based on vaccine supply rather than science. These are few instances of increasing politicization of key regulatory bodies, unexplained decisions during trial procedures, frequent changes in the policies, blanket statements about different vaccines which have created evident public confusion. Publishing the data for public scrutiny will make people more aware and help increase vaccine 
science literacy rather than leaving a vacuum where vague theories can propagate. ${ }^{27,28}$

\section{EMPATHY}

The communication from the government needs to convey the concern that it understands the suffering of the community. The government has rightly framed the policies considering the major fear among people which is the high mortality rate from COVID-19 in the 45 plus age group with co-morbid conditions. In the initial stage, they have included this group in the priority list so that this set of population would be covered first. In all his speeches, the Prime Minister has tried to touch the emotional chord of people and asked them to follow all covid related protocols and get vaccinated. He has highlighted the government's concern for the states, its people, and efforts for the procurement of vaccines. He even urged the youth of this country to help the old and sick people in getting the vaccine in time. The low turnout of beneficiaries in the rural areas, owing to language (English) and technological barrier (CoWin platform) were dealt with on-spot registrations at the vaccination sites. At the ground level, the healthcare staff involved in vaccination should also convey empathy towards the beneficiaries. Clear messages displaying important information about vaccination and one-to-one addressing of concerns are effective ways to do it.

\section{FACTUAL CONTEXT}

The uncertainties regarding vaccine safety, epidemiological facts have raised concerns. Nevertheless, this is not unique to India and the realm of information is constantly being updated. The GOI should embrace these uncertainties and highlight what government can do and is doing. It should be presented in the form of facts as to what is still unknown and what constraints are being faced. For example, when there were speculations regarding 'emergency approvals' of the vaccine it is necessary to highlight that the technological advancements in vaccine technology, multiple parallel trials, increased funding, help from regulatory authorities, political will were all responsible for experts working at higher speed and development of a safe vaccine. ${ }^{14}$

\section{INVALIDATE RUMORS}

Managing the COVID-19 pandemic and protecting from misinformation is crucial to fight the pandemic. ${ }^{29}$ Special groups are the worst affected but, most ignored. Rumors are generated when there is a lack of transparency about available information or a delay in the release of information by a trusted source. Addressing these rumors via HRC should be done to alleviate anxiety among people and rebuild trust. This is an iterative process. Ironically in India, many of the rumors are started by political and religious leaders often as a political 'gimmick' and circulated by media without verification. ${ }^{30}$ This however cannot be generalized, and wherever possible the leaders should try to debunk conspiracy theories around vaccination frequently. HCWs who are working at ground level should make every attempt at invalidating false information.

Rumors circulating vaccination are not new. Unscientific claims regarding vaccination are many- vaccines cause impotency, vaccines contain pork, vaccines contain microchips, vaccines alter DNA, vaccines cause 'magnetism' in the body, etc. Many of these claims have been debunked by drug regulators such as DCGI and the Government. ${ }^{12,31}$ The press information bureau released many documents busting myths and facts regarding vaccination which is quite helpful. Attempt to do this frequently and make the answers transparent will go a long way. ${ }^{32}$ Use of social media in debunking myths by using official Twitter handles of the ministry or Health minister is also a good strategy. ${ }^{12}$ It is imperative that information sent by the trusted sources be verified and do not endorse any hypothesis.

\section{MEDIA MONITORING}

The ongoing Covid pandemic has compounded vaccinerelated myths and misinformation. Community behaviour can be easily influenced by information given by the media. On one hand, when we are trying to increase acceptance and confidence in vaccination, on the other hand, myths about vaccination targeting religious sentiments, mistrust on authorities, and unscientific claims are being published in social media, print media and aired on news channels as well. ${ }^{30,31,33}$ In addition to this, media debates on the science behind vaccine development and the fairness of the process are being discussed. The scientific jargon makes it difficult for the common man to differentiate facts from speculative hypotheses. To make matters worse, reports of the CEO of SII and Chairman of Bharat Biotech engaged in a war of words is sensationalized and the joint statement issued as clarification later deserves just petty attention. ${ }^{34,35}$ Coordinated efforts from all stakeholders are necessary to prevent such mishaps from happening in the future. Any form of media must refrain from sensationalizing vaccine-related myths and deaths due to unknown causes. Only relevant and confirmed scientific materials which can be easily comprehended should be put out. Additional responsibility to publish or air refuted hypothesis should be taken up. Media should become channels to understand people's needs and identify barriers to effective HRC.

\section{CONCLUSION}

Efforts against COVID-19 vaccination are at a crucial juncture now where vaccination for the largest group 1844 years is rolled out. Trust and confidence in the vaccine have never been more important. With an increasing number of healthcare staff vaccinated, the confidence in the general public needs to be increased. Hesitancy in special groups needs to be urgently addressed. Increased 
transparency and clear answers about facts that are known or unknown, procurement and allocation need to be maintained. Sensationalizing vaccine-related myths, deaths due to unknown causes must be stopped. The media must prioritize vaccine-related news to relevant and confirmed scientific materials only. Responsibility to air refuted hypotheses based on rumours should be taken up by the media houses.

\section{Funding: No funding sources \\ Conflict of interest: None declared \\ Ethical approval: Not required}

\section{REFERENCES}

1. Andre FE, Booy R, Bock HL, Clemens J, Datta SK, John TJ, et al. Vaccination greatly reduces disease, disability, death and inequity worldwide. Bull World Health Organ. 2008;86(2):140-6.

2. World Health Organisation (WHO). Emergencies preparedness, response safety of pandemic vaccines. 2009;(August):3-5

3. Kamradt-Scott A. The International Health Regulations (2005): Strengthening Their Effective Implementation and Utilisation. Int Organ Law Rev. 2019;16(2):242-71.

4. Singh P, Dhawan V, Rishi G. COVID-19 vaccine communication strategy. New Delhi; 2021. Available at: https://www.mohfw.gov.in/pdf/ Covid19CommunicationStrategy2020.pdf. Accessed on 21 May 2021.

5. National Risk Communication Plan. New Delhi; 2016. Available at: https://ncdc.gov.in/WriteReadData/1892s/File593.pd f. Accessed on 21 May 2021.

6. Sarojini N, Deepa V. Trials and tribulations: an expose of the HPV vaccine trials by the $72^{\text {nd }}$ Parliamentary Standing Committee Report. Indian J Med Ethics. 2013;10:220-2.

7. Communication for polio eradication and routine immunization Checklists and easy reference guides WHO, UNICEF, USAID (Basic II and Change projects). 2002 Available at: https://www.who.int/ biologicals/publications/meetings/areas/vaccines/pol io/PolioCommsChklsts.pdf?ua=1. Accessed on 11 June 2021.

8. COVID-19 vaccine communication strategy released - Express Healthcare. Available at: https://www.expresshealthcare.in/news/covid-19vaccine-communication-strategy-released-healthministry/426676/. Accessed on 11 June 2021.

9. Prime Minister reviews status of COVID-19 and preparedness for COVID-19 vaccination [Internet]. Ministry of Health and Family Welfare. 2021 Available at: https://pib.gov.in/PressReleasePage. aspx?PRID=1687305. Accessed on July 5, 2021.

10. Chat on WhatsApp with MyGov Corona Helpdesk. Available at: https://api.whatsapp.com/send/ ?phone=919013151515\&text=Hi\&app_absent $=0$. Accessed on 21 May 2021.
11. India Fights Corona (@COVID News By MIB)/Twitter. Available at: https://twitter.com/ COVIDNewsByMIB. Accessed on 21 May 2021.

12. Dr. Harsh Vardhan on Twitter: "There is no scientific evidence to suggest that \#COVIDVaccine could cause infertility in either men or women. Kindly do not pay heed to such rumours or information from unverified sources. \#Stay Informed Stay Safe @PMO India @MoH. Available at: https://twitter.com/drharshvardhan/status/ 1349687664639762435?s=20. Accessed on 14 June 2021.

13. Survey Shows Rising Vaccine Hesitancy Threatening COVID-19 Recovery. Press releases. World Economic Forum. Available at: https://www.weforum.org/press/2020/11/surveyshows-rising-vaccine-hesitancy-threatening-covid19-recovery/. Accessed on 21 May 2021.

14. Rzymski P, Zeyland J, Poniedziałek B, Małecka I, Wysocki J. The perception and attitudes toward COVID-19 vaccines: a cross-sectional study in Poland. Vaccines. 2021;9:7-13.

15. Sircar S. We need to identify and eliminate vaccine hesitancy among healthcare workers. Available at: https://science.thewire.in/health/healthcare-workersvaccine-hesitancy/. Accessed on 20 April 2021.

16. Healthcare workers declining COVID-19 vaccine is a matter of sadness: Government. Available at: https://www.businesstoday.in/latest/trends/healthcar e-workers-declining-covid-19-vaccine-is-a-matterof-sadness-govt/story/428431.html. Accessed on 20 April 2021.

17. COVID-19 vaccine: $74 \%$ scheduled health workers didn't get second shot out of every eligible, both the doses are taken. Available at: https://www. downtoearth.org.in/news/health/covid-19-vaccine-

74-scheduled-health-workers-didn-t-get-secondshot-75570\#: :text=Three. Accessed on 20 April 2021.

18. Viswanath K, Rn H, Singh Basra S, Chourey N. Corona virus disease 2019 vaccination drive: the perceptions and acceptance of vaccination among health care workers. Asian J Pharm Clin Res. 2021;14:20-1.

19. Singhania N, Kathiravan S, Pannu AK. Acceptance of coronavirus disease 2019 vaccine among healthcare personnel in India: a cross-sectional survey during the initial phase of vaccination. Clin Microbiol Infect. 2021;9:23-7.

20. Press Statement by the Drugs Controller General of India (DCGI) on Restricted Emergency approval of COVID-19 virus vaccine. Available at: https://pib.gov.in/PressReleseDetail.aspx?PRID=16 85761. Accessed on 29 June 2021.

21. Ella R, Reddy S, Blackwelder W, Potdar V, Yadav P. Efficacy, safety and lot to lot immunogenicity of an inactivated SARS-CoV-2 vaccine (BBV152): a double-blind, randomised, controlled phase 3 trial. medRxiv Prepr. 2021;27-35. 
22. The National Regulator grants Permission for Restricted Use in Emergency Situations to Sputnik$\mathrm{V}$ vaccine. Available at: https://pib.gov.in/Press ReleasePage.aspx?PRID=1711342. Accessed on 29 June 2021.

23. PM addresses the Nation. Available at: https://pib.gov.in/PressReleasePage.aspx?PRID=172 5113. Accessed on 29 June 2021.

24. Govt. is committed to transparency in COVID vaccination programme: Health Ministry. Available at: https://www.livemint.com/politics/policy/govt-iscommitted-to-transparency-in-covid-vaccinationprogramme-health-ministy-11623315428048.html. Accessed on 29 June 2021.

25. India's vaccine policy requires transparency Hindustan Times. Available at: https://www. hindustantimes.com/opinion/indias-vaccine-policyrequires-transparency-101622297613150.html. Accessed on 29 June 2021.

26. Fadnavis faces flak as 22-year-old nephew Tanmay gets COVID-19 vaccine. Deccan Herald. Available at: https://www.deccanherald.com/national/west/ fadnavis-faces-flak-as-22-year-old-nephew-tanmaygets-covid-19-vaccine-976427.html Accessed on 5 July 2021.

27. Cohen AF, van Gerven J, Burgos JG, de Boer A, Foucher RAM, Flore H, et al. COVID-19 vaccines: the importance of transparency and fact-based education. Br J Clin Pharmacol. 2020;86(11):210710.

28. We Need More Transparency in COVID-19 Vaccine Development. Time. Available at: https://time.com/ 5890216/transparency-covid-vaccine-development/. Accessed on 29 June 2021.

29. Managing the COVID-19 infodemic: promoting healthy behaviours and mitigating the harm from misinformation and disinformation. Available at: https://www.who.int/news/item/23-09-2020managing-the-covid-19-infodemic-promotinghealthy-behaviours-and-mitigating-the-harm-frommisinformation-and-disinformation. Accessed on 29 June 2021.
30. India Covid-19: Misleading claims shared about vaccines- BBC News. Available at: https://www.bbc.com/news/55768656 Accessed on 14 June 2021.

31. COVID-19 vaccines $110 \%$ safe, impotency rumours complete nonsense: DCGI. India News- Times of India. Available at: https://timesofindia.indiatimes. com/india/covid-19-vaccines-110-safe-impotencyrumours-complete-nonsense-dcgi/articleshow/8008 2000.cms Accessed on 14 June 2021.

32. Myths \& Facts on India's Vaccination Process. PIB. NITI Aayog. 2021. Available at: https://pib.gov.in/PressReleasePage.aspx?PRID=172 2078. Accessed on 11 June 2021.

33. Coronavirus vaccine will be a way of injecting people with microchips? Don't fall for this Facebook hoax- Times of India. Available at: https://timesofindia.indiatimes.com/life-style/healthfitness/health-news/coronavirus-vaccine-will-be-away-of-injecting-people-with-microchips-dont-fallfor-this-facebook-hoax/articleshow/78404956.cms. Accessed on 14 June 2021.

34. Krishna Ella on Poonawalla's 'Safe, Like Water' Remark on Vaccine. Available at: https://www. thequint.com/news/india/krishna-ella-on-adarpoonawalla-safe-like-water-remark-onvaccine\#read-more. Accessed on 21 May 2021.

35. Vaccine firms Bharat Biotech, Serum Institute patch up after war of words. Business Standard News. 2021. Available at: https://www.businessstandard.com/article/current-affairs/vaccine-firmsbharat-biotech-serum-institute-patch-up-after-warof-words-121010500995_1.html. Accessed on 11 June 2021.

Cite this article as: Shah AK, Pal S. Overview of health risk communication strategies in the context of COVID-19 vaccination in India. Int J Community Med Public Health 2022;9:1091-6. 